\title{
O imaginário do trabalho em saúde mental: Elementos para discussão
}

\author{
The mental health work imaginary: Elements for discussion
}

\author{
Vinicius Carvalho de Vasconcellos
}

Mestre em Saúde Pública pela Escola Nacional de Saúde Pública, Fundação Oswaldo Cruz (ENSP/Fiocruz), psicólogo da Petrobras, Rio de Janeiro, RJ - Brasil, e-mail: v.v@click21.com.br

\section{Resumo}

Este artigo tem como objetivo identificar os elementos imaginários que recobrem o exercício do trabalho em saúde mental em um Centro de Atenção Psicossocial (CAPS), examinando também de que maneira esse imaginário traz impactos para a relação do profissional com seu trabalho. Com o intuito de atingir esse objetivo, utilizou-se do referencial teórico da psicossociologia francesa contemporânea e o discurso de profissionais da área, a partir dos quais emergiram representações sobre o exercício do trabalho e suas vivências organizacionais. Tal investigação extraiu seu material empírico de uma pesquisa de campo realizada no ano de 2007, em um CAPS do município do Rio de Janeiro, Brasil. Nesta análise, o imaginário do trabalho em saúde mental surge ancorado em um ideal de mudança positivado, pautado principalmente na reforma psiquiátrica, processo apropriado subjetivamente por meio da formulação de três grandes núcleos de representações: regime/local de assistência, relação assistencial e relação sociedade/ loucura. Detectou-se igualmente no imaginário uma imagem de fragilidade/incerteza, sobre os resultados do trabalho e a condução dos casos, que derivou em uma relação com o trabalho marcada pelo rebaixamento de expectativas. Na coexistência e na alquimia que mistura esses elementos no cotidiano da organização, surge uma inesperada composição que busca assegurar a própria continuidade do trabalho.

Palavras-chave: Saúde mental. Reforma psiquiátrica. Subjetividade.

\section{Abstract}

This article aims to identify the imaginary elements that recover the exercise of the work in mental health in a Centro de Atenção Psicossocial (CAPS), examining also how this imaginary brings impacts to the relation between the professional and his work. To fulfill this objective, it was used the theoretical basis of the French school of 
psychosociology and the professionals' speech of the area, from which surfaced representations of the exercise of the work and their organizational experiences. This investigation extracted its empirical material from a field research carried out in 2007 within a CAPS of Rio de Janeiro, Brazil. In this analysis, the imaginary of the work in mental health appears anchored in an ideal of change made positive, ruled principally in the psychiatric reform, process appropriated subjectively through the formulation of three great nucleuses of representations: type/place of assistance, assistencial relation and society/madness relation. An image of fragility/uncertainty was equally detected in the imaginary of the results of the work and conduction of the cases, which causes a relation with the work marked by the reduction of expectations. In the coexistence and in the alchemy that mix these elements, appears an unexpected composition that tries to secure the continuity of the work.

Keywords: Mental health. Psychiatric reform. Subjectivity.

\section{Introdução}

A história do conhecimento e do tratamento da loucura não passou indene à ação inexorável do tempo e das mudanças políticas, sociais e econômicas. Os sobressaltos, as latências, as rupturas e a microfísica das relações humanas e sociais promovem um intrincado plexo de laços que cria, na diacronia das concepções e das práticas sobre a loucura, um enredo intrincado. $\mathrm{Na}$ historiografia recente do tratamento da loucura, as cercanias da Segunda Guerra Mundial assistiram à instigante ebulição de proposições contrapostas ao modelo manicomial, que foi sustentado, desde os fins do século XVIII, na internação, no isolamento social, na exclusividade do saber/poder médico e no tratamento disciplinare moral dos loucos (Pitta, 1996; Foucault, 1978; Castel, 1978; Birman, 1978).

Independente dos motivos e dos diferentes graus de extensão que embasaram essas transformações, o fato é que germinaram, a partir do pós-guerra, reformas psiquiátricas em diversos países (Desviat, 1999; Amarante, 1995; Melman, 2001). No final da década de 1970, tal movimento aporta no Brasil, tornando as políticas e práticas assistenciais vigentes alvos de críticas e manifestações veementes, dentre os quais é possível destacar da "crise da Dinsam" (Divisão Nacional de Saúde Mental). Como um relevante marco desse processo, tal crise configurouse como uma greve nos mais importantes serviços psiquiátricos do Rio de Janeiro, tendo por mote a denúncia das irregularidades nas condições de trabalho e de assistência. Posteriormente, ocorreu a criação do Movimento de Trabalhadores em Saúde Mental (MTSM), desdobramento da tensão política gerada na ocasião (Amarante, 1995).
As reivindicações trabalhistas, as reclamações acerca da privatização da assistência e as críticas ao modelo hospitalocêntrico plasmaramse em uma rede de contestações, a partir da qual surge um espaço de discussão sobre o caráter do tratamento psiquiátrico no Brasil. Desde então, a reforma psiquiátrica ganhou expressão e influência na rede de saúde mental do País, indo além de uma modernização ou um aggiornamento, posto que além de permitir a formulação de políticas públicas e a criação de modelos tecnoassistenciais, o movimento comporta também em seus muros iniciativas nos planos teórico-conceitual, jurídico-político e sociocultural (Amarante, 1997).

Nesse cenário, o trabalho em saúde mental tornou-se foco de muitas produções acadêmicas, interessadas, sobretudo, em estudar as aplicações das políticas públicas do setor ou em avaliar o sucesso ou fracasso de determinadas práticas ou serviços assistenciais. Em contraste, o recorte dado ao presente artigo privilegiou, a partir da narrativa dos profissionais da área, a dimensão imaginária que permeia as práticas assistenciais e seus desdobramentos para a relação desses profissionais com seu próprio trabalho.

O endereçamento para a dinâmica imaginária do trabalho utilizou como referência as bases conceituais da psicossociologia francesa, campo teórico que se debruça sobre a intersubjetividade no trabalho e no mundo das organizações. Registra-se que, no campo da saúde pública em geral, a ênfase na intersubjetividade já propiciou contribuições originais no estudo dos serviços de saúde (Azevedo, 2002; Azevedo, Braga Neto \& Sá, 2002; Sá, Carreteiro \& Fernandes, 2008) de forma que este artigo se coaduna a tal esforço, enfocando, nesse caso, a área da saúde mental. 
O material empírico que compõe este artigo foi extraído de uma pesquisa maior (Vasconcellos, 2008) e originou-se de um estudo de campo realizado em um Centro de Atenção Psicossocial (CAPS) da cidade do Rio de Janeiro. Esta pesquisa maior, valendo-se do mesmo referencial teórico anteriormente mencionado, buscou compreender a relação entre a dinâmica do trabalho em saúde mental e três macrocenários que a envolvem: a sociedade contemporânea, o Sistema Único de Saúde (SUS) e a reforma psiquiátrica brasileira.

\section{A reforma psiquiátrica e o atual contexto da saúde mental brasileira}

A tentativa de escandir o imaginário do trabalho em saúde mental deve, necessariamente, ser precedida pela contextualização do conjunto de transformações vividas por esse campo nas últimas décadas, cujo principal artífice foi o movimento pela reforma psiquiátrica. Este, logo após a crise da Dinsam, ganhou novos capítulos, como, por exemplo, na realização de diversos congressos acadêmicos e fóruns que trataram de ampliar e reverberar as discussões sobre os (des)caminhos da assistência psiquiátrica no País (Amarante, 1995; Bezerra Jr., 1994; Delgado, 1992). Concomitante às discussões nos congressos, espraiaram-se as ideias de Foucault, Castel, Basaglia, Szasz entre os profissionais de saúde mental e ocorreu o boom da psicanálise no Brasil, configurando um contexto intelectual contestador e reflexivo que toma as cátedras acadêmicas (Bezerra Jr., 1994).

Paulatinamente, as propostas da reforma, incluindo em linhas gerais o questionamento do modelo hospitalocêntrico e manicomial, passaram a ecoar nas instâncias governamentais. Ainda no começo da década de 1980, o Ministério da Saúde redigiu o documento Diretrizes para a área de saúde mental, no qual defende a ênfase no tratamento extrahospitalar, a limitação do período de internação, a reintegração familiar e a promoção de pesquisas epidemiológicas no campo da saúde mental (Brasil, 1980). Em seguida, a insidiosa ocupação de postos de chefia, no maquinário estadual e nos municípios, por quadros progressistas do MTSM agenciou um salto qualitativo no processo, encurtando os caminhos rumo à concretização dos ideais reformistas (Amarante, 1995).
Inicialmente, a reforma psiquiátrica investiu na estratégia de ambulatorização como forma de minimizar o acento dado pelo regime militar à internação. Tal proposta arrefeceu significativamente em função do relativo malogro da iniciativa, assaz vincada por consultas meramente farmacológicas, grandes filas de espera, baixa resolutividade e aumento de internações; além disso, a estratégia ambulatorial acabou sendo interpretada, muitas vezes, como uma ampliação do controle social da psiquiatria (Levcovitz, 2000; Silva Filho, 2000; Tenório, 2000).

Por via de consequência, a formulação de propostas que ultrapassassem o ambulatório fazia-se premente. A substituição do modelo manicomial, centrado na hospitalização, ganhou nova expressão com o advento de moradias protegidas, hospitais dia, hospitais noite, residências terapêuticas, dispositivos que, trabalhando de várias formas e com distintas inserções, percorriam uma nova trilha no tocante à problemática da assistência à loucura.

Nessa ampliação do leque de opções assistenciais, os CAPS transformaram-se em ícones representativos da reforma psiquiátrica brasileira. Documentos recentes do Ministério da Saúde (Brasil, 2004) elevam os CAPS à condição de organizadores da rede de cuidados em saúde mental, incluindo em sua proposta a necessidade de uma equipe interdisciplinar. Essa exigência se baseia na assunção de que a contribuição de diferentes profissionais à assistência torna esta mais potente e abrangente, evitando a exclusividade médica no trato com a loucura que caracterizava o modelo hospitalocêntrico e manicomial. Entre os objetivos do CAPS, despontam a substituição do modelo hospitalocêntrico, a diminuição das internações e o favorecimento do exercício da cidadania e da inclusão social dos usuários e de suas famílias (Brasil, 2004).

Essa guinada nas políticas públicas decerto foi influenciada pela mobilização gerada pela reforma psiquiátrica brasileira. Esta, além de defender o fim da preeminência dos hospitais na assistência, traz em punho outras bandeiras afins como a territorialização da assistência, a defesa da participação ativa das famílias, dos usuários, dos trabalhadores e da comunidade no tratamento, a busca pela garantia de acesso/acolhimento dos usuários nos serviços de saúde, além da construção da cidadania destes (Brasil, 2002).

Entretanto, seé possível abalizar a existência de bandeiras relativamente consensuais na reforma 
psiquiátrica, isso não esconde a heterogeneidade do movimento. Desse modo, como sublinha Bezerra Jr. (1999, p. 135), "quando se trata de propor um novo modelo de cuidados na saúde mental, vai se tornando claro que a convergência dos que são 'anti' o manicômio esconde, na realidade, muitas perspectivas diferentes". Reformas dentro da reforma: assim deve serencarada a heterogeneidade teórica/metodológica das proposições que vieram a (re)pensar as práticas vigentes no Brasil.

Nessa conjuntura, que inclui a consolidação das políticas públicas, por um lado, e a atuação de um heterogêneo movimento de reforma, por outro, adquire especial interesse em investigar as feições assumidas pelo imaginário que envolve o trabalho em saúde mental e sua influência na relação profissional/trabalho. A literatura da área começa a rastrear os elementos que transpassam essa relação no atual contexto da saúde mental brasileira, ainda que se valendo de caminhos teóricos e metodológicos distintos. Garcia e Jorge (2006), calcados na abordagem fenomenológicahermenêutica, desvelam os trabalhadores de um CAPS mergulhados, ao mesmo tempo, na tradição psiquiátrica e na possibilidade de reforma, processo que envolve, no universo experiencial de cada um, sofrimento psíquico e dúvidas no modo de conduzir ações.

Similarmente, Koda e Fernandes (2007) destacam que, embora os códigos norteadores das práticas manicomiais sejam considerados inadequados pela maioria dos profissionais, eles asseguravam um firme modelo de conduta aos técnicos, de modo que o questionamento desses códigos traz, em consequência, a perda de estabilidade social e psicológica. Oliveira e Alessi (2005), utilizando como referencial teórico-metodológico a dialética marxista, apontam para a necessidade dos trabalhadores se constituírem como sujeitos sociais e cidadãos, dessa feita, construindo uma relação com o trabalho pautada pelo espírito crítico e pela capacidade de rupturas diante das práticas hegemônicas de controle social. Por sua vez, as relações interpessoais nas equipes são realçadas por Silva e Costa (2008) como relevantes para as vivências profissionais dos trabalhadores dos CAPS, ainda que essas relações possam assumir uma duplicidade de papéis: podem servir tanto como ponto de apoio e alívio quanto como fonte de conflitos e injustiças.

\section{A psicossociologia francesa e o imaginário nas organizaçóes}

Buscando complementar e aprofundar as investigações precedentes, privilegiar o estudo do imaginário que permeia o exercício laboral, este artigo se remete à relação profissional/trabalho a partir de outra fonte teórica, a saber, a psicossociologia francesa. Filiada ao campo maior da psicossociologia, a psicossociologia francesa contemporânea é uma vertente teórico-prática que tem como campo privilegiado de estudo os grupos, as organizações e as comunidades em situações cotidianas. Ela orienta seus estudos a partir da premissa que os indivíduos não se vinculam às organizações somente por liames instrumentais, monetários, racionais ou materiais, o que permite a essa abordagem criar outra cena de investigação. De fato, de acordo com Freitas (2000, p. 42):

As organizações não são apenas lugares onde o trabalho é executado. São também lugares onde sonhos coexistem com pesadelos, onde o desejo e as aspirações podem encontrar espaço para a realização, onde a excitação e o prazer da conquista convivem com a angústia do fracasso [...]. Elas são alimentadas pela emoção, pela fantasia, pelos fantasmas que cada ser humano abriga em si.

Seguindo essa linha, o acento da análise recai nos processos intersubjetivos e nas dimensões imaginária e simbólica compartilhadas pelos membros das organizações (Enriquez, 1997), sempre apreciando o cruzamento de matizes psíquicos e sociais na expressão da dinâmica organizacional. A relação profissional/trabalho também é posta em evidência, emergindo sempre atrelada às necessidades narcísicas dos profissionais e suas experiências de realização e fracasso. Para tanto, a psicossociologia francesa apoia-se no manancial conceitual da psicanálise - em especial nas obras de cunho sociológico de Freud - e no discurso dos sujeitos, valorizando-os em sua profundidade e na sua capacidade de representar a realidade social e de construir sentidos para ela (Sá, 2005).

No enfoque dado a este artigo, o trabalho em saúde mental será examinado exatamente a partir do imaginário que o circunscreve e da 
relação profissional/trabalho. Cumpre mencionar, de antemão, que o termo "imaginário" encontra polissemia, seja no senso comum, seja nas ciências humanas e sociais. Por exemplo, no senso comum é frequente o estabelecimento de sinonímia entre o termo "imaginário" e o termo "ilusório", o que empresta ao primeiro uma ideia de falsidade.

Mais recentemente, despindo-se da antiga equivalência com a ideia de ilusão ou com a ideia de cópia, o imaginário passou a ser visto como um conceito e uma categoria analítica importante na explicação das condutas humanas. Ator e um dos protagonistas dessa inflexão, Castoriadis (1982), ao tratar do imaginário de uma sociedade ou de uma época, refere-se a isso como criação ex nibilo e incessante de figuras/formas/imagens a partir das quais é possível falar-se de "alguma coisa". O imaginário é capaz de dar funcionalidade a um sistema institucional, sendo fonte de significados e de certa maneira de ver, viver e fazer sua própria existência (Castoriadis, 1982).

A psicossociologia francesa retoma em boa medida o imaginário tal como concebido por Castoriadis, utilizando-o de forma mais restrita, como fenômeno organizacional e grupal. Traspassado pela dimensão inconsciente, o imaginário na psicossociologia francesa exprime-se como uma força produtiva capaz de influenciar a dinâmica social, estando ligado ao conjunto de representações e desejos circulantes em uma coletividade (Giust-Despraires, 2002). Este pode assumir, como ressalta Freitas (2000, p. 48), o papel de ser "o 'local' por excelência do projeto a construir, do mundo melhor, do sonho, da fantasia, do desejo".

Por essa razão, o liame entre o imaginário e a constituição de projetos coletivos ganha importância nos caminhos teóricos da psicossociologia francesa. Para Enriquez (1994), a efetivação de tais projetos encontra-se apoiada inelutavelmente na existência de um imaginário comum, que representa o grupamento social nas suas aspirações e em sua autoimagem e, desse modo, torna os indivíduos fiadores de algo que os transcende. $\mathrm{O}$ autor alerta, todavia, que para serem operantes, essas representações não devem ser apenas pensadas intelectualmente, mas igualmente sentidas, ou seja, devem traduzir afetos.

Posto isso, cumpre sinalizar que este artigo objetiva identificar os elementos imaginários que recobrem o exercício do trabalho em saúde mental em um CAPS - incluindo a inserção da reforma psiquiátrica nesse contexto e sua possibilidade de figurar como um projeto coletivo - e examinar de que maneira esse imaginário traz impactos para a relação dos profissionais com seu próprio trabalho. Tal empreitada mostra sua relevância, posto que o imaginário e a relação profissional/trabalho são elementos que influenciam sobremodo o exercício das práticas assistenciais, de modo que conhecê-los em profundidade é um passo importante para propiciar uma assistência de qualidade para os usuários dos serviços de saúde mental.

\section{Métodos}

Este estudo configura-se como uma pesquisa qualitativa e apoia-se na ideia de que há uma relação inseparável entre o mundo real e a subjetividade dos atores (Minayo Souza, Constantino, \& Santos, 2005). A eleição do método qualitativo relaciona-se ao enfoque teórico da psicossociologia francesa, que concebe as organizações como sistemas dinâmicos, complexos e multifacetados, enfatizando o aspecto intersubjetivo das práticas organizacionais. Parte-se do princípio de que as imagens e as representações emergentes em uma organização não figuram como uma contrapartida especular de um mundo exterior e tangível, mas, ao contrário, elas mostram os sentidos que fecundam e integram visceralmente a própria realidade.

Dentro dos diversos desenhos metodológicos englobados na seara da pesquisa qualitativa, este estudo delineia-se como uma pesquisa de campo, valendo-se como universo de investigação de um CAPS. Essa escolha encontra respaldo na condição de organizador da rede de saúde mental assumida pelos CAPS, o que credita ao dispositivo uma posição de centralidade e que o transforma em um sítio privilegiado de estudo.

O serviço pesquisado foi o CAPS Arthur Bispo do Rosário, situado na zona oeste da cidade do Rio de Janeiro e, mais especificamente, dentro dos limites do Complexo Juliano Moreira. Esse amplo complexo de serviços, uma das instituições psiquiátricas mais tradicionais da cidade do Rio de Janeiro e do Brasil, hoje abriga, em sua vastidão, diversos dispositivos de saúde mental, a maior parte deles sob a guarda do Instituto Municipal de Assistência à Saúde 
Vasconcellos, V. C. de.

Juliano Moreira (IMASJM). O período de pesquisa de campo estendeu-se pelos meses de agosto e setembro de 2007 e, no total, foram realizadas aproximadamente 20 visitas ao Bispo do Rosário. Duas estratégias foram privilegiadas nesta pesquisa: a observação participante e as entrevistas semiestruturadas. A observação participante centrou-se na atuação dos profissionais no fluxo de usuários, no brechó do serviço, na assembleia de usuários, no grupo de referência e na reunião de equipe/supervisão, sendo acompanhada porum diário de campo, no qual foram transcritas as percepções relativas ao campo da pesquisa.

Por sua vez, as entrevistas foram semiestruturadas, sendo utilizadas com o intuito de lançar os entrevistados na busca de sentidos para sua experiência. Dentro do enfoque teórico-metodológico proposto, pressupõe-se que as entrevistas expressam não só as representações, os valores e crenças do entrevistado em sua individualidade, mas colocam este na condição de porta-voz daquela organização, facultando assim a apreensão de elementos imaginários compartilhados pela coletividade.

A seleção de profissionais para as entrevistas foi pautada por dois critérios formais: a) estar envolvido diretamente nas práticas assistências; b) trabalhar há pelo menos um ano no CAPS Bispo do Rosário, tempo que fornece maior capacidade reflexiva e narrativa sobre o serviço. Dentro desses parâmetros, existiu um único critério de exclusão que se refere à possibilidade do profissional recusar o convite para ser entrevistado. O conjunto de entrevistas abrangeu profissionais de nível superior e de nível médio, oriundos de diferentes formações profissionais. Salvaguardadas as condições de seleção dos participantes assinaladas acima, o serviço dispunha de 11 profissionais elegíveis para a entrevista, de sorte que, ao término da pesquisa de campo, oito profissionais foram entrevistados, quantitativo próximo ao próprio universo da pesquisa. As entrevistas foram individuais e realizadas no próprio local de trabalho, usando como locação os consultórios, a biblioteca ou o pátio da instituição. Sua duração média foi de aproximadamente uma hora.

Servindo como etapa obrigatória para a consecução da pesquisa de campo, o projeto de pesquisa foi submetido ao Comitê de Ética em Pesquisa da Fiocruz (CEP/Fiocruz) e ao Comitê de Ética em Pesquisa do IMASJM (CEP/IMASJM), comitê de referência para o CAPS em tela. Precedendo todas as entrevistas e práticas observadas, o Termo de Consentimento Livre e Esclarecido foi lido e assinado, de maneira que o objeto da pesquisa foi exposto e o anonimato dos participantes, afiançado.

\section{Resultados e discussáo}

O Bispo do Rosário é formalmente cadastrado, dentro da tipologia proposta pelo Ministério da Saúde, como um CAPS II, apresentando na época da pesquisa cerca de 280 usuários cadastrados. O serviço contempla em seus atendimentos homens e mulheres adultos e, a respeito da constelação de figuras clínicas, o perfil concentra-se nas psicoses e neuroses graves. Trata-se de serviço já consolidado em seu território, tanto pelo seu tempo de funcionamento (foi inaugurado em 1998) como por ser a referência regional no tipo de atendimento que presta. Além disso, o Bispo do Rosário conta com uma equipe multiprofissional e oferta para a sua clientela modalidades assistenciais dentro dos parâmetros prescritos pelas políticas públicas da área.

No concurso da pesquisa de campo, um dos elementos do imaginário que logo foi trazido à baila revelou o trabalho em saúde mental revestido por caráter" "nobre" e"bonito". Aoproporcionarassistência a um segmento da população excluído socialmente e que se về às voltas com o sofrimento psíquico - sendo, porconseguinte, tão necessitado-,o profissional toma para si a responsabilidade de acolher os usuários. Tal arranjo leva os profissionais a enxergarem "beleza" em seu trabalho, gerando um valor positivo para o trabalho e uma imagem que recompensa narcisicamente os profissionais.

Nosso papel aqui é o acolbimento, a escuta e dar todo o tratamento. É muito importante. Principalmente o acoIbimento dos técnicos é muito bonito (Profissional A).

O trabalho é muito bom, muito bonito. Cansativo mas gratificante, porque demanda muito. Você se doa bastante porque vê que tem muita gente precisando [...] mas no término do dia você se sente gratificada (Profissional B).

De fato, por intermédio da crença da maioria dos profissionais no valor positivo de 
seu trabalho, engendra-se, nos dizeres de Kaës (1991), uma aderência narcísica à tarefa primária, isto é, uma identificação favorável com a missão da instituição. Essa aderência favorece uma boa relação com o trabalho, propiciando o investimento psíquico dos técnicos nas suas práticas e gratificação profissional.

Essa valoração positivada do trabalho assume contornos ainda mais expressivos quando o potencial da assistência em inspirar mudanças na vida dos usuários consegue se materializar em casos reais, ainda que os exemplos não tenham sido tão frequentes nas entrevistas.

O CAPS é um espaço de cuidado, superlegal, que faz. diferençapara ospacientes, comoporexemplo o., paciente novo, que a gente viu a transformação até facial dele, de como ele chegou, e esse éo CAPS. Essa transformação é ocasionada pelo CAPS, e ele disse "o CAPS conseguin me transformar dessa forma" (Profissional C).

O paciente se assustava com o trabalho protegido e quando começava a melhorar ele entrava em crise. A gente conseguiu sustentar e acompanbar e ele pôde no final dizer que ele se identificava como cidadão. É a marca dessas pequenas mudanças na clínica que a gente pode estar construindo. É o CAPS conseguindo tecernovas formas de identificações e novas formas de estar no mundo (Profissional D).

Todavia, o signo da mudança, que nas citações acima surge na microfísica do encontro assistencial, parece estar conectado, no fundo, a uma reformulação maior que transformou o panorama da saúde mental brasileira. É nesse sentido que as falas dos profissionais do CAPS realçam a inserção de seu trabalho no contexto maior da reforma psiquiátrica. Tal filiação subjetiva pode ser resumida, por exemplo, na entrevista de uma profissional que, ao ser perguntada sobre o significado de trabalhar no CAPS, responde, de pronto:

significa trabalhar em um serviço de ponta da reforma psiquiátrica. É uma instituição que visa substituir o antigo modelo asilar, que já provou que não tem um efeito terapêutico, que é supercondenável, e precisa ser mesmo substituido por outro tipo de modelo, a reforma psiquiátrica. Trabalhar aqui é um motivo de orgulho (Profissional E).
Nesse caso, o orgulho sentido pelo técnico denota a filiação do indivíduo aos ideais da reforma, o que depõe, como visto anteriormente, sobre a capacidade de experimentar afetos que favorecem a efetivação do projeto coletivo. Tal filiação funciona a reboque de um processo de idealização, a partir do qual se canaliza o desejo para o projeto e instaura-se a certeza sobre sua veracidade (Enriquez 1994). De fato, tanto as entrevistas quanto a observação de campo apoiam a asserção de que os preceitos da reforma psiquiátrica foram alçados à condição de referência a ser perseguida pelos profissionais, penetrando capilarmente no serviço e mediando a relação técnico/usuário.

Assim, o imaginário da reforma emerge como um imaginário motor, ou seja, capaz de fecundar o real por meio do desejo dos profissionais e de levar os membros de uma organização a percebê-la de outra forma, mormente a partir da criação de uma fantasmática compartilhada que permite o exercício da experimentação e da transformação (Azevedo, 2005). No rastro do supradito, se o imaginário do trabalho surgiu na pesquisa de campo, referenciado em larga medida à reforma psiquiátrica, cumpre investigar de que maneira essa última se traduziu no discurso dos entrevistados, isto é, quais elementos foram destacados na teia heterogênea e complexa da reforma e como eles se relacionam.

Coerente com o signo da mudança aventado anteriormente, a pesquisa de campo sugere que as representações da reforma foram forjadas por meio do estabelecimento de uma estrutura de antinomias, que instaura uma marcação temporal que opõe o antes (assistência manicomial) ao depois (reforma psiquiátrica). Se essa forma de construção não gera grande surpresa, posto que os valores da reforma psiquiátrica foram erigidos na brasa do confronto com o modelo manicomial, por outro lado, elas também reserva certas nuanças que tornam seu exame mais complexo e, por via de consequência, justificado. Dessa forma, a análise das entrevistas forneceu três grandes núcleos de representações para significar o processo de mudança, cada um deles acompanhado por uma antinomia que opõe o modelo de assistência manicomial ao modelo de assistência da reforma psiquiátrica (Tabela 1): 
Vasconcellos, V. C. de.

Tabela 1 - Núcleos de representações da oposição entre a assistência manicomial e a reforma psiquiátrica brasileira no CAPS Bispo do Rosário

\begin{tabular}{lll}
\hline Núcleos de representações & Assistência manicomial & $\begin{array}{l}\text { Assistência da reforma } \\
\text { psiquiátrica }\end{array}$ \\
\hline Regime/local de tratamento & Internação/hospital & Atenção diária/serviços substitutivos \\
Relação assistencial & Cuidado médico/maus-tratos & $\begin{array}{l}\text { Equipe multiprofissional/ } \\
\text { humanização }\end{array}$ \\
Relação sociedade/loucura & Isolamento/preconceito & Inserção social \\
\hline
\end{tabular}

Fonte: Pesquisa de campo realizada no CAPS Bispo do Rosário. Brasil, 2007.

A disposição dos núcleos de representações na Tabela 1 respeita a força e a visibilidade de cada um deles nas entrevistas. Dessa forma, as representações do núcleo regime/ local de assistência mostraram-se mais frequentes e mais incrustadas no imaginário, sendo mencionadas em sete dos oito entrevistados, seguidas por aquelas referentes à relação assistencial e por aquelas concernentes à relação sociedade/loucura. Esses dois últimos núcleos figuraram, respectivamente, em quatro e três entrevistas.

Em última instância, esses três núcleos estão profundamente interligados entre si. $\mathrm{Na}$ medida em que o cuidado sai do binômio hospitalização/ internação e que o tratamento pauta-se nas premissas de integralidade e interdisciplinaridade, torna-se mais viável atuar na (re)inserção social do louco e na relação sociedade/loucura. Contudo, o objetivo aqui é grifar, dentre as várias referências possíveis na heterogeneidade da reforma psiquiátrica, quais se apresentam de forma mais consistente no imaginário estudado e como elas foram apropriadas subjetivamente.

O primeiro desses núcleos, o regime/ local de tratamento, sublinha aspectos organizacionais e mais concretos da assistência, fazendo emergir as oposições internação $x$ atenção diária (no caso do regime de tratamento) e hospital x serviços substitutivos (no caso do local de tratamento). Assim, quando os entrevistados eram convidados a falar sobre a reforma, a criação de novos serviços e a diminuição das internações eram as representações mais pregnantes.

Antes era como era. Hoje eu vejo grande progresso. E isso se deve à luta de muitosprofissionais e com certeza não foi fácil chegar até aqui. Só o fato de quando o paciente dar uma crise e o profissional não conter, não levar para o hospital, já é um grande progresso. [...] Porque antigamente qualquer coisa era hospital. Por muito menos se internava. [...] Hoje em dia no CAPS você já pode tratar as pessoas (Profissional B).

A gente avancou muito do que era e tem efeitos na assistência. Temos que falar na criação de novos serviços e em estatística: a gente tem uma redução absurda no numero de pessoas internadas (Profissional F).

A discussão sobre as características dos locais de atendimento esteve presente desde o início da reforma psiquiátrica brasileira. No caso dos CAPS, a escolha ordinariamente recai sobre imóveis próximos aos centros comerciais e desprovidos de matizes institucionais. Nesses termos, a interação com o território flui de forma mais rica e o desejável contato com as cercanias mantém os usuários próximos à cotidianidade de uma residência qualquer. A opção por casas ou outras edificações não hospitalares sustenta-se também na sensação de acolhimento e de subjetivação do espaço que estas podem proporcionar aos usuários. Visceralmente atrelado ao local da assistência, o regime de tratamento cumpre sobremaneira a função de contraste entre modelo manicomial e a reforma psiquiátrica no discurso dos entrevistados. A maioria destes vincula linearmente a internação ao modelo manicomial e a assistência diária à reforma psiquiátrica. Nessa linha, esse novo momento da assistência recobre-se imaginariamente com a missão última de refrear as internações.

Por exemplo, ter que internar um paciente é uma coisa que eu não aceito. Teve uma vez que fiquei chateada 
porque tinha um paciente que ia internar e eu disse não, vamos aguentar até mais tarde, não precisa não, vamos tentar conversar (Profissional B).

O segundo núcleo de representações, a relação assistencial, desvela a reforma eminentemente como um movimento capaz de inspirar transformações no trato com os usuários do serviço, seja por humanizar a assistência, seja por torná-la mais plural e interdisciplinar no que se refere às possibilidades de cuidado. Nesse núcleo, as representações apontam para a superação tanto dos maus-tratos quanto da exclusividade do paradigma médico-psiquiátrico do modelo manicomial.

Se você comparar com o modelo antigo, manicomial, as possibilidades são de dar um suporte às pessoas que sofrem tanto. Passa a ser dar esse suporte de uma maneira muito mais humana, muito mais eficaz, mais ética do que acontecia antes (Profissional G).

Euvejo que ele (o CAPS) tentaprestaruma assistência integral dentro do que prega a reforma psiquiátrica. [...] É uma instituição que visa substituir o antigo modelo asilar. A gente tenta prestar uma assistência aos pacientes de maneira integral, tentando vê-los a partir de vários aspectos, tanto psiquiátrico, psicológico, social (Profissional E).

Com efeito, se é inegável que a proposta de equipe interdisciplinar opera como fulcro para o desenvolvimento da reforma psiquiátrica, é também verdadeiro que ela torna mais complexa a dinâmica intersubjetiva na relação profissional. Em sua análise sobre a questão, Onocko Campos (2003) pontua que as equipes da maioria dos serviços de saúde padece com padrões de relacionamentos interpessoais fincados na ameaça que o outro representa, fracassando na constituição de áreas intersubjetivas que permitam a experiência da diferença como uma vivência não mortal. Por seu turno, Gomes, Pinheiro e Guizardi (2005) defendem que os atritos entre diferentes formações profissionais são explicados em parte pela transposição automática, para o campo de trabalho coletivo, dos constructos teóricos nos quais cada profissão/saber assenta seus pilares de ação.

Decerto, existe uma tendência dos saberes permanecerem cada qual encerrado em suas concepções gnosiológicas de loucura, em suas atribuições protocolares ou em seus interesses corporativos, o que guarda relação com o fato da identidade profissional se solidificar por intermédio de um processo de formação que, geralmente, não privilegia a integração com outras disciplinas. Malgrado essa tendência, a interdisciplinaridade é basilar para a melhoria da assistência, tendo em vista que ela almeja apenas uma integração técnica, mas, sobretudo, uma alteração na concepção do cuidado. Daí a necessidade de se investir na própria capacidade da equipe de negociar seus papéis, rediscutir os saberes e criar novos consensos (Onocko Campos, 2000).

O núcleo de representações relação sociedade/ locura, conforme assinalado anteriormente, foi aquele que apareceu com menor frequência e intensidade no conjunto das falas dos profissionais. Os fragmentos de entrevistas agrupados neste núcleo referem-se basicamente a comentários dos participantes da pesquisa acerca da inserção do louco na sociedade. Incluídos nesse bojo estão desde trechos que comentam sobre a necessidade de tornar a sociedade mais receptiva e aberta à loucura até o incentivo à ressocialização por meio do trabalho.

Sem dúvida, o raciocinio que se teve há 20 anos atrás éum raciocinio totalmente equivocado. Essa tentativa de ressocializar da reforma psiquiátrica é muito válida e quando é possivel eu tento ir nessa direção (Profissional H).

Tolerância à loucura. Acho que a grande palavra da reforma psiquiátrica brasileira é respeito e tolerância ao que é diferente, ao que tem uma dificuldade maior de existir. E acho que, através disso, nós temos conseguido ganhos na comunidade. Tolerar mais um vizinho que fala mais alto. A família tolerar mais aquele membro que age diferente, mais estranho, às vezes bizarro, mas que nem por isso deve ser excluído da família, da comunidade (Profissional E).

Dentro das possibilidades da reforma psiquiátrica, o foco na relação sociedade/loucura é, em boa medida, tributário da influência basagliana e da faceta sociopolítica da reforma (Bezerra Jr. 1994, 1999), sendo provavelmente um dos pontos que menos evoluiu na atual conjuntura da saúde mental do País. Nesse contexto, há um deslizamento no eixo da questão, de forma que a discussão sobre a problemática da loucura (sua definição e sua assistência) deve transcender a clínica (em seu sentido estrito) e se reportar à sociedade, pois nela se encontram os mecanismos originários de marginalização. 
A transformação da relação loucura/ sociedade afigura-se realmente como um objetivo audacioso, todavia imprescindível para promover um salto de qualidade na assistência à loucura. Sem essa transformação, as imagens de periculosidade, intratabilidade, incapacidade e bizarrice, que acompanham o louco na sua condição social de "doente mental", culminam em preconceito, obstaculizando muitas vezes uma inserção social efetiva.

Se o trabalho em saúde mental, conforme exposto anteriormente, vem investido psiquicamente por meio de uma imagem que põe em relevo sua "beleza" e o signo da mudança, cuja linha mestra é a filiação ao projeto de reforma psiquiátrica, isso não significa, no entanto, que esse mesmo trabalho quede-se imaginariamente imune a outras influências. Em primeiro lugar, o jogo de antinomias citado acima, que separa com perfeição a assistência manicomial da assistência pautada pela reforma, opera na tentativa de delimitar áreas de fronteira, descortinando-se como um expediente que, em tese, facilitaria a localização do trabalho diante da dupla referência. Entretanto, a irretocável separação na arena representacional não encontra inteiro respaldo nas situações cotidianas dos serviços, nas quais muitas ações terapêuticas estão suscetíveis à dúvida de ser ou não manicomiais, ainda que sob a roupagem da reforma psiquiátrica. Essa imprecisão é sinalizada no exemplo a seguir, no qual um técnico, ao ser perguntado se percebia alguma prática ainda capturada pela lógica manicomial, declarou:

\begin{abstract}
quando a gente far aqueles passeios com muita gente, por exemplo, é uma coisa que me deixa bem dividido; porque, de um lado, você está proporcionando uma circulação pelo território; por outro, você está indo para o território em uma situação muito especifica, com um monte de gente junto. Mas a gente não costuma fazer isso aqui, mas até faz. (Profissional G).
\end{abstract}

Esse profissional mostra suspeição quanto à conotação assumida por essa prática. De uma parte, reconhece que os passeios podem favorecer os usuários em sua ligação com o território; de outra, se questiona se essas saídas em massa trazem efetivamente benesses terapêuticas e sociais para cada usuário, tendo em vista que podem ser entendidas como uma distração tutelada e não como um trabalho territorial. Dessa forma, outro profissional ressalta: não tenho isso ainda elaborado, mas acho que, em alguns momentos, algumas situações clínicas do CAPS sofriam intervenções que eu nomearia de manicomiais, não porque as pessoas estavam sendo negligentes ou irresponsáveis sobre aquilo, mas porque se tinha uma tentação de dar conta de tudo, não dar conta de tudo que a reforma propõe, mas em um viés manicomial (Profissional F).

Com efeito, no cotejamento das premissas da reforma psiquiátrica com determinadas circunstâncias da cena assistencial, surge a possibilidade de se encontrar uma sombra manicomial, entendida como a subsistência de práticas / situações tipicamente atribuídas ao tratamento moral e ao modelo manicomial. Essa possibilidade instaura, na subjetividade dos próprios técnicos, um processo de julgamento crítico capaz de flagrá-los atuando sob a égide de traços manicomiais. Em certas ocasiões, esse julgamento não consegue discernir entre a dupla referência presente no jogo de antinomias, levando os profissionais a pôr em xeque suas próprias práticas assistenciais.

Entretanto, o esforço para implantar uma nova forma de assistência traduz-se não somente em debelar sombras do passado manicomial, mas também em conseguir concretizar os ideais e consolidar as práticas nascidas do processo de reforma. Essa tarefa galvaniza, por certo, grandes desafios, não só pelas dificuldades intrínsecas à consecução do projeto de reforma, e pelas intensas demandas por cuidado dos usuários, mas igualmente porque coloca os técnicos confronte um contexto caracterizado pelas insuficientes condições de trabalho no SUS. Nesse enquadramento, a efetivação plena das propostas da reforma pode acabar revestida por um tom de dúvida sobre suas reais possibilidades de implantação.

Em certo sentido, na reforma psiquiátrica há uma
tentação de assegurar coisa demais, não sei se nós temos
pernas para isso. E isso tudo dentro de certa escassez. de
recurso, e de uma coisa permanente de ter que construir
e reconstruir, rede, inventividade, criação, sustentação
de vínculo difícil (Profissional F).

Outro ponto que merece atenção acerca do imaginário que recobre a realização do trabalho, notadamente no que tange ao bom andamento da assistência, é a incerteza e a imprevisibilidade vivenciada pelos profissionais na condução dos casos. Considerando a complexidade das psicoses 
e das neuroses graves, a incerteza cruza o cuidado como uma torrente, como nas situações em que as intervenções assistenciais ou a evolução dos usuários adquirem contornos inesperados. O inapreensível da loucura encontra par na surpresa advinda de uma ação assistencial da qual se esperava resultados que não vieram, ou de um ato aparentemente inócuo que poderia acarretar avanços terapêuticos.

A gente lida com a incerteza o tempo todo sobre o que vai acontecer. [...] Às vežes você sua a camisa para fazer um negócio achando que vai ser interessante para o paciente e não vê resposta nenbuma e de repente você está passando no corredor e dá um "tchauzinho" e depois de três anos ele lembra e diz "você me deu o 'tchauzinho' e isso mudou a minha vida". Claro que estou exagerando, mas esse tipo de coisa acontece muito. A gente não tem muito controle sobre o que a gente far. A gente vê resultados, mas é muito difícil de mensurar, de entender, de provocar e de controlar (Profissional G).

Tem alguma coisa nisso ai que a gente chama de loucura que é estranho, que trazpara a gente uma angústia e uma impotência absurda. A gente vêpessoas que a gente estabiliza um tempão, em um dado momento aquilo vai ruir de novo (Profissional $\mathrm{F}$ ).

Esse cenário de desconhecimento e incertezas por vezes empresta uma imagem de fragilidade ao trabalho, posto que, a qualquer momento, tudo pode ruir ou mudar bruscamente. Com efeito, essa fragilidade cobra seu preço dos profissionais na forma de mal-estar, dada que a baixa governabilidade dos atos assistenciais dificulta a sensação de domínio sobre o exercício do próprio trabalho. Esse domínio cumpre uma função psíquica tranquilizadora, essencialmente por meio da capacidade de antever os efeitos de suas ações e, assim, manipulá-los com maior desenvoltura.

Como corolário desse processo, as representações ligadas à instabilidade e à incerteza da assistência não deixam intocadas as expectativas relacionadas aos resultados do trabalho. Por exemplo, os dois trechos a seguir atestam uma forma peculiar de se relacionar com o trabalho, a partir da qual as expectativas devem ser rebaixadas ou mesmo não devem existir, sob pena de gerarem decepção.
Acho que do tratamento da loucura não é possivel esperar nada. Porque se você espera você se frustra. É o que acontece muitas vezes, fica na expectativa e se frustra. Vocêfrustrado, vocêdesanima e você desanimado, você não trata. A gente não tem que ter expectativa. (Profissional C).

Depende do caso do paciente, de quem está tratando, do conhecimento e das loucuras de quem está tratando. Só não pode esperar muita coisa. Você tem que se surpreender. Quando você espera é que nada vem. É um trabalho de surpresas (Profissional G).

Convém atentar para o trabalho psíquico aqui demandado, isto é, o policiamento das próprias expectativas. Esse mecanismo desnuda a tentativa de equiparar as expectativas ao baixo grau de certeza e de controle dos profissionais acerca dos resultados, impedindo que as primeiras sejam solapadas pela inconstância e desabem na forma de frustração. Cumpre, dessa maneira, uma função psíquica regulatória, já que, de uma parte, amortece a sensação de frustração.

\section{Consideraçóes finais}

As transformações no campo da saúde mental brasileira abarcam, em sua amplitude, construções teóricas, a criação de novos serviços e práticas, a promulgação de leis e portarias e iniciativas de cunho sociocultural. Em última instância, tais transformações culminam em um novo paradigma assistencial, calçado na formação de um novo olhar sobre a loucura, que redesenhou o elo profissional/ usuário. Similarmente, esse processo engendra uma nova relação profissional/trabalho, influenciada por transformações no imaginário que atravessam a realização da assistência.

Durante a pesquisa de campo, detectouse a reforma psiquiátrica como a mola mestra de um imaginário motor que, sob o signo da mudança, foi capaz de impulsionar os profissionais na busca contínua por uma nova assistência. Inseridos nesse projeto coletivo, os profissionais conseguem, apesar de várias adversidades, formular uma imagem positiva do trabalho, mormente em função de sua capacidade de mudar a vida dos usuários do serviço. 
Todavia, ao aprofundar o estudo de como os profissionais se apropriam dos elementos discursivos da reforma, percebeu-se um predomínio deveras acentuado do rechaço à internação e à hospitalização. Uma possível explicação para essa configuração repousa na constatação de que aludir ao regime e local de assistência é um modo mais concreto, simples e objetivo de se referir à reforma do que trazer à baila outras referências, como a relação sociedade/ loucura ou a relação assistencial. Daí a hipótese de que a força da representação manifesta-se de maneira inversamente proporcional ao nível de complexidade e de abstração por ela requerida.

Ainda assim, tal predomínio desse núcleo não escamoteia dois riscos intrínsecos. Em primeiro lugar, caso levado ao paroxismo, esse direcionamento pode se transmutar em uma repulsa absoluta à internação/ hospitalização, banindo-a do conjunto de possibilidades terapêuticas dos profissionais. Esse banimento pode traduzir uma visão simplista, pois descarta uma opção terapêutica que, se usada com base em critérios rígidos e por um período curto de tempo, pode ser benéfica para certos usuários. Registra-se que alguns profissionais do CAPS, cônscios desse risco, deixam transparecer em suas falas a possibilidade do bom uso da internação.

Olha que eu não tenho nada contra a internação. Em alguns momentos a pessoa precisa ser internada. Parece que toda a internação é má, e não é (Profissional F).

Em adição, o segundo risco concerne ao entendimento de que a força desse núcleo pode, na verdade, sinalizar uma redução do ideário da reforma. Os profissionais, ao se concentrarem apenas na mudança de regime e local da assistência, podem acabar preterindo outros pontos da reforma, notoriamente a discussão acerca do lugar do louco na sociedade brasileira, que apareceu de forma mais tímida nas entrevistas. As análises de Costa (2000) e Sá (2005) apontam que a configuração social no Brasil cada vez mais é trespassada por um modo de subjetivação que patrocina a exclusão social e produz um alheamento diante dos desfavorecidos, dentre os quais os loucos se inserem. Nessa vereda, é possível que o foco no primeiro núcleo ajude a encobrir essa questão societária, muito mais ampla e complexa, limitando a potência das transformações no campo da saúde mental no País. Se é verdade que os três núcleos detectados na pesquisa estão concatenados e mostram a presença dos ideais da reforma no exercício do trabalho, é mister envidar esforços para que a potência de um dos núcleos não apague a importância dos demais.

Por sua vez, o sistema representacional de antíteses que separa, a preceito, a assistência manicomial da assistência baseada na reforma parece não se reproduzir com perfeição nas microcenas da assistência. A princípio encerrada nos princípios da reforma, a condução de algumas práticas assistenciais pode despertar dúvidas sobre a possível reprodução de uma lógica manicomial. Se, por um lado, esse movimento pode trazer algum mal-estar aos profissionais, tendo em vista que apaga as confortáveis e supostamente nítidas fronteiras entre os dois modelos na arena representacional, por outro lado, a existência dessa crítica parece fundamental para a evolução da assistência, na medida em que impede o engessamento das práticas e promove o constante questionamento do cuidado dispensado.

Simultaneamente, o trabalho surgiu na pesquisa revestido por imagens de fragilidade e incerteza no que tange à consecução e à manutenção de bons resultados no cuidado. Nesse contexto, convém salientar que a própria implantação da reforma trouxe em sua esteira um novo quadro de referência, no qual a obtenção de êxitos assistenciais são muito mais desafiadores do que antes, visto que incluem objetivos complexos como, por exemplo, a reinserção social. Adicionalmente, cumpre ponderarainfluência negativa das inadequadas condições de trabalho e da falta de investimento no desenvolvimento de recursos humanos nos serviços, empecilhos para a obtenção de resultados. Diante dessa conjuntura, detectou-se um rebaixamento no nível de expectativa dos profissionais com relação aos resultados, mecanismo que age regulando as possibilidades de frustração e realização no trabalho.

Nesse sentido, poder-se-ia caracterizar certa ambivalência no que se refere à sua relação com o trabalho: por um lado, há investimento psíquico na reforma psiquiátrica ena possibilidade de obter resultados a partir de um imaginário motor de mudança; por outro, na cotidianidade do serviço, desponta imagens da fragilidade da assistência e um rebaixamento das expectativas de êxito nos casos. Por derradeiro, caberia perguntar ainda se, no trabalho em saúde mental, esses dois polos formariam uma contradição em si. No fundo, a relação dos profissionais com o trabalho parece assentada na coexistência desses elementos, em que os primeiros contrabalançam os últimos, em uma composição que busca assegurar a própria continuidade do trabalho. 


\section{Agradecimentos}

Agradecimento especial ao CNPq pelo financiamento parcial da pesquisa, aos profissionais do CAPS Bispo do Rosário por sua colaboração e à professora Creuza da Silva Azevedo pela orientação da pesquisa durante o mestrado.

\section{Referências}

Amarante, P. (1995). Loucos pela vida: A trajetória da reforma psiquiátrica no Brasil. Rio de Janeiro: Fiocruz.

Amarante, P. (1997). Loucura, cultura e subjetividade: Conceitos e estratégias, percursos e atores da Reforma Psiquiátrica Brasileira. In S. Fleury (Org.). Saúde e democracia: A luta do CEBES (pp. 163-185). São Paulo: Lemos Editorial.

Azevedo, C. S., Braga Neto, F. C., \& Sá, M. C. (2002). O indivíduo e a mudança nas organizações públicas de saúde: Contribuições da psicossociologia. Cadernos de Saúde Pública, 18(1), 235-47.

Azevedo, C. S. (2002) Liderança e processosintersubjetivos em organizações públicas de saúde. Revista Ciência \& Saúde Coletiva, 7(2), 349-61.

Azevedo, C. S. (2005). Sob o domínio da urgência: O trabalho de diretores de hospitais públicos do Rio de Janeiro. Tese de Doutorado, Instituto de Psicologia da Universidade de São Paulo, São Paulo.

Bezerra Jr., B. (1994). De médico, de louco e todo mundo um pouco: o campo psiquiátrico no Brasil dos anos 80. In R. A. Guimarães \& R. Tavares (Org.). Saúde e Sociedade no Brasil: Anos 80 (pp. 171-191). Rio de Janeiro: Relume-Dumará.

Bezerra Jr., B. (1999). A diversidade no campo psiquiátrico: Pluralidade ou fragmentação. Cadernos IPUB, 14, 135-144.

Birman, J. (1978). A psiquiatria como discurso da moralidade. Rio de Janeiro: Graal.

Brasil. Ministério da Saúde (1980). Diretrizes para a área de saúde mental. Brasília: Ministério da Saúde.

Brasil. Ministério da Saúde (2002). III Conferência Nacional de Saúde Mental: Relatório final. Brasilia: Ministério da Saúde.
Brasil. Ministério da Saúde (2004). Saúde mental no SUS: Os centros de atenção psicossocial. Brasilia: Ministério da Saúde.

Castel, R. (1978). A ordem psiquiátrica: A idade de ouro no alienismo. Rio de Janeiro: Graal.

Castoriadis, C. (1982). A instituição imaginária da sociedade. Rio de Janeiro: Paz e Terra.

Costa, J. F. (2000). A ética democrática e seus inimigos. In A. Roitman (Org.). O desafio ético (pp. 77-89). Rio de Janeiro: Garamond.

Delgado, P. G. (1992) As razões da tutela: Psiquiatria, justiça e cidadania do louco no Brasil. Rio de Janeiro: Te Corá.

Desviat, M. (1999). A reforma psiquiátrica. Rio de Janeiro: Fiocruz.

Enriquez, E. (1994). O vínculo grupal. In A. Lévy, A. Nicolaï, E. Enriquez \& J. Dubost (Org.). Psicossociologia: Análise social e intervenção (pp. 24-40). Petrópolis: Vozes.

Enriquez, E. (1997). A organização em análise. Petrópolis: Vozes.

Foucault, M. (1978). História da loucura na idade clássica. São Paulo: Perspectiva.

Freitas, M.E. (2000). A questão do imaginário e a fronteira entre a cultura da organização e a psicanálise. In M. E. Freitas \& F. C. Prestes Motta (Org.). Vida psíquica e organização (pp. 11-22). Rio de Janeiro: FGV.

Garcia, M. L. P., \& Jorge, M. S. B. (2006). Vivência de trabalhadores de um centro de atenção psicossocial: Estudo à luz do pensamento de Martin Heidegger e Hans-Georg. Ciência \& Saúde Coletiva, 11(3), 765-774.

Gomes, R. S., Pinheiro, R., \& Guizardi, F. L. (2005). A orquestração do trabalho em saúde: Um debate sobre a fragmentação das equipes. In R. Pinheiro \& R. A. Mattos (Org.). Construção social da demanda: Direito à saúde, trabalho em equipe, participação e espaços públicos (pp. 105-116). Rio de Janeiro: CEPESC/UERJ; ABRASCO.

Giust-Deprairies, F. (2002). Representation et imaginaire. In J. Baurus-Michel, E. Enriquez, \& A. Lèvy (Org.). Vocabularie de psychosociologie (pp. 231-250). Paris: Éres. 
Kaës, R. (1991). A Instituição e as instituições. São Paulo: Casa do Psicólogo.

Koda, M. Y., \& Fernandes, M. I. A. (2007). A reforma psiquiátrica e a constituição de práticas substitutivas em saúde mental: Uma leitura institucional sobre a experiência de um núcleo de atenção psicossocial. Cadernos de Saúde Pública, 23(6), p. 1455-1461.

Levcovitz,S. (2000). Grupos de recepção ambulatorial: Uma introdução ao tema. Cadernos do IPUB, 6(17), 21-29.

Melman J. (2001). Família e doença mental: Repensando a relação entre profissionais de saúde e familiares. São Paulo: Escrituras.

Minayo, M. C. S., Souza, E. R., Constantino, P., \& Santos, N. C. (2005). Métodos, técnicas e relações em triangulação. In M. C. S. Minayo, S. G. Assis, \& E. R. Souza (Org.). Avaliação por triangulação de métodos: Abordagem de programas sociais (pp. 71-103). Rio de Janeiro: Fiocruz.

Oliveira, A. G. B., \& Alessi, N. P. (2005). Cidadania: Instrumento e finalidade do processo de trabalho na reforma psiquiátrica. Ciência \& Saúde Coletiva, 10(1), 191-203.

Onocko Campos, R. (2000) Análise do planejamento como dispositivo mediador de mudanças institucionais com base em um estudo de caso. Cadernos de Saúde Pública, 16(4), 1021-1030.

Onocko Campos, R. (2003). A gestão: Espaço de intervenção, análise e especificidades técnicas. In G. W. S. Campos. Saúde Paidéia (pp. 122-149). São Paulo: Hucitec.

Pitta, A. (1996). Ética e assistência em psiquiatria. In J. F. Silva Filho \& A. C. Figueiredo. Ética e saúde mental (pp. 123-126). Rio de Janeiro: Topbooks.

Sá, M. C. (2005). Em busca de uma porta de saída: Os destinos da solidariedade, da cooperação e do cuidado com a vida na porta de entrada de um hospital de emergência. Tese de Doutorado, Instituto de Psicologia da Universidade de São Paulo, São Paulo.

Sá, M. C., Carreteiro, T. C., \& Fernandes, M. I. A. (2008). Limites do cuidado: Representações e processos inconscientes sobre a população na porta de entrada de um hospital de emergência. Cadernos de Saúde Pública, 24(6), 1334-1343.
Silva Filho, J. F. (2000). O ambulatório e a psiquiatria. Cadernos IPUB, 6(17), 115-122.

Silva,E. A., \& Costa, I. I. (2008) Saúde mental dos trabalhadores em saúde mental: Estudo exploratório com os profissionais dos Centros de Atenção Psicossocial de Goiânia-GO. Psicologia em Revista, 14(1), 83-105.

Tenório, F. (2000). Desmedicalizar e subjetivar: A especificidade da clínica da recepção. Cadernos IPUB, 6 (17), 79-91.

Vasconcellos V. C. (2008). A dinâmica do trabalho em saúde mental: Limites e possibilidades na contemporaneidade e no contexto da reforma psiquiátrica brasileira. Dissertação de Mestrado, Escola Nacional de Saúde Pública, Fundação Oswaldo Cruz, Rio de Janeiro.
Recebido: 02/02/2010

Received: 02/02/2010

Aprovado: 30/06/2010

Approved: 06/30/2010 